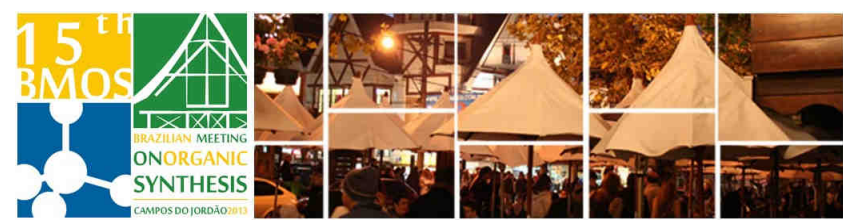

\title{
Synthesis of new biologically actived azaspiro compounds
}

\section{Lucimara J. Martins ${ }^{1 *}$, Wanessa F. Altei ${ }^{2}$, Cristiane S. Schwalm ${ }^{1}$, Adriano D. Andricopulo ${ }^{2}$ and Fernando Coelho ${ }^{1}$}

${ }^{1}$ University of Campinas - Chemistry Institute - PO Box 6154 - 13083-970 - Campinas, SP, Brazil; ${ }^{2}$ Computational and Medicinal Chemistry Laboratory, Centre of Structural Molecular Biotechnology, Institute of Physics of São Carlos, USP, 13560-970, São Carlos, SP, Brazil. *lucmartins@iqm.unicamp.br

Keywords: Morita-Baylis-Hillman, azaspiro, antiproliferative profile

\section{INTRODUCTION}

Recently we have developed a methodology for the synthesis of spirocyclohexadienones ${ }^{1,2,3}$. These compounds showed moderate antibacterial activity, but good antiproliferative activities.

The initial studies on the applications of PBN ( $\alpha$ phenyl-tert-butylnitrone) and its derivatives for trapping free radicals in chemical systems ${ }^{1}$ associated with the antiproliferative activity exhibited by spirocyclohexadienones, such as Gimnastatin I$\mathrm{K}^{2}$ and Griseofulvin ${ }^{3}$ compounds, stimulated us to evaluate the synthesis and biological profile of some azaspiro derivatives. In this communication we disclosed the synthesis and the biological screening of new azaspiro compounds from Morita-BaylisHillman adducts.

\section{RESULTS AND DISCUSSION}

The nitrogen atom of our target compounds was introduced through the formation of oximes. So, the treatment of Heck adducts ( $\beta$-ketoesters) with hydroxylamine hydrochloride gave a diastereomeric mixture of oximes, in which the $E$ cyclizes spontaneously to the corresponding isoxazolones. Table 1: Preparation of azaspiro compounds

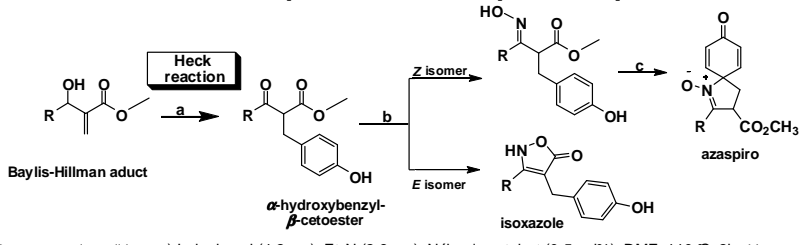

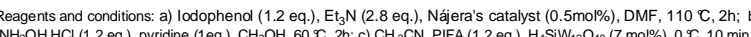

\begin{tabular}{|c|c|c|c|}
\hline \multicolumn{2}{|c|}{$\beta$-ketoesters ${ }^{a}$} & Oxime $(\mathrm{Z})^{\mathrm{a}}$ & azaspiro $^{a}$ \\
\hline $\mathrm{R}=\mathrm{Ph}-$ & $1(91)$ & $11(44)$ & $21(38)$ \\
\hline $\mathrm{R}=4-\mathrm{CF}_{3} \mathrm{Ph}-$ & $2(75)$ & $12(43)$ & $22(61)$ \\
\hline $\mathrm{R}=3,5-\mathrm{F}_{2} \mathrm{Ph}-$ & $3(74)$ & $13(46)$ & $23(38)$ \\
\hline $\mathrm{R}=4-\mathrm{NO}_{2} \mathrm{Ph}-$ & $4(71)$ & $14(45)$ & $24(26)$ \\
\hline $\mathrm{R}=4-\mathrm{BrPh}-$ & $5(37)$ & $15(37)$ & $25(44)$ \\
\hline R = Piperonil- & $6(68)$ & $16(25)$ & $26(34)$ \\
\hline $\mathrm{R}=3,4,5-(\mathrm{OMe})_{3} \mathrm{Ph}-$ & 7 (82) & $17(32)$ & 27 (42) \\
\hline $\mathrm{R}=4-\mathrm{OMePh}-$ & $8(73)$ & $18(25)$ & $28(48)$ \\
\hline $\mathrm{R}=3-\mathrm{OMePh}-$ & $9(97)$ & $19(34)$ & 29 (39) \\
\hline $\mathrm{R}=N$-nonil- & $10(75)$ & $20(24)$ & $30(21)$ \\
\hline
\end{tabular}

*Yields (\%) refer to isolated and purified products.
The oxime $Z$ was treated with PIFA to furnish the new azaspiro compounds 21-30 (Table 1).

The structure of new azaspiro compound was confirmed by single crystal $\mathrm{X}$-ray diffraction analysis (Figure 1).

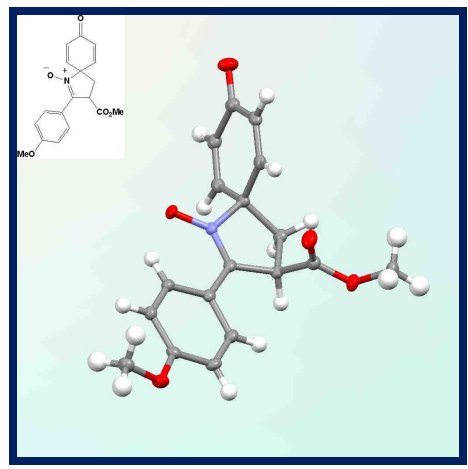

Figure 1: Crystal X-ray diffraction analysis of azaspiro 28

When screened against some strains of human cancer cells these azaspiro compounds showed a good anti-antiproliferative profile. The complete evaluation of the biologic profile of them is ongoing. Attempts to control the selectivity during the formation of oximes are under study. The success of this control could improve the overall yield of the methodology.

\section{CONCLUSION}

In clonclusion, we synthesized for the first time new functionalized azaspiro compounds from MoritaBaylis-Hillman. The sequence is simple and furnishes the required products in moderate overall yield (over three steps). The complete biological profile of this compounds are under investigation and the results will be disclosed in the due time.

\section{ACKNOWLEDGEMENTS}

The authors thank Fapesp (2009/18390-4), CNPq and Capes for financial support.

\section{REFERENCES}

${ }^{1}$ Ferreira. B. R. V.; Pirovani, R. V.; Souza-Filho, L. G.; Coelho, F. Tetrahedron, 2009, 65, 7712. ${ }^{2}$ Pirovani, R. V.; Ferreira, B. R. V.; Coelho, F. Synlett, 2009, 2333. ${ }^{3}$ Zhdankin, V. V.; Stang, P. J. Chem. Rev. 2008, 108, 5299. ${ }^{4}$ Basavaiah, D.; Badsara, S. S.; Veeraraghavaiah, G. Tetrahedron, 2013, 69, 7995. ${ }^{5}$ Amagata, T.; Takigawa, K.; Minoura, K.; Numata, A. Heterocycles 2010, 81, 897. ${ }^{6}$ Rønnest, M. H. et al. J. Med. Chem. 2009, 52, 3342. 